Case Report

\title{
Contravention Between NPV \& IRR Due to Timing of Cash Flows: A Case of Capital Budgeting Decision of an Oil Refinery Company
}

\author{
Sayan Banerjee \\ Department of Business Management, Goenka College of Commerce \& Business Administration, Kolkata, West Bengal, India
}

Email address:

sayanbanerjee895@gmail.com

\section{To cite this article:}

Sayan Banerjee. Contravention Between NPV \& IRR Due to Timing of Cash Flows: A Case of Capital Budgeting Decision of an Oil Refinery Company. American Journal of Theoretical and Applied Business. Vol. 1, No. 2, 2015, pp. 48-52. doi: 10.11648/j.ajtab.20150102.13

\begin{abstract}
Purpose of the study: This write up aims at exploring the causality between the timing of cash flows and contravention of Net Present Value and Internal Rate of Return as regards capital budgeting decision. Background of the study: It is neither too often found that Net Present Value and Internal Rate of Return are leading to neither contradiction nor have the topic been given much thrust. The endeavour is to bring this burning issue in light with the help of a practical case in an oil refinery factory. Methodology: Discounting technique has been used in the formulae to compute Net Present Value and Internal Rate of Return. Results: The study shows possibility of contravening results in case of mutually exclusive projects. Findings: It is found that due to severity of discounting factor, timing of cash flows of projects lead to contradicting results as depicted by Net Present Value and Internal Rate of Return.
\end{abstract}

Keywords: Capital Budgeting, Net Present Value, Internal Rate of Return, Timing of Cash Flows, Project

\section{Introduction}

The corporate finance observes capital budgeting is encompassed by project recognition, project expansion, choice of project and project control. Capital budgeting decision is one of the most important and critical decisions that a finance manager has to take. It is through capital budgeting decision a firm selects the best possible investment avenues (Projects) to deploy its funds into long term assets. Capital budgeting decision has vivid impact on a firm's long term growth and sustainability as shareholders wealth maximization, operating cost, profitability and risk complexity of a firm are dependent variables of capital budgeting decision. Academic studies have shown the technical soundness of cash discount models, such as the NPV in capital budgeting decision. Volkman (1997) developed yield-based capital budgeting method that is commensurate with shareholders wealth maximization principle.

Christian Kalhoefer (2010) showed that problem of ranking of mutually exclussive projects using NPV and IRR is due to insufficient application of the investment appraisal techniques.
Aho \& Virtanen (1982) explored the relationship between ROI and IRR under inflation. Weber (2014) introduced the selective IRR, a return criterion which is NPV-consistent.

It is important to know that a capital budgeting decision is irrevocable or revocable at substantial cost. It is imperative to gain an insight into some basic elements for the sake of our discussion.

Independent Investments (Projects):

In the cases of independent projects each and every project serves a different purpose and they do not compete with each other regarding their selections. All profitable projects can be selected upon availability of funds. Ex-A heavy engineering company plans to increase its existing capacity and also to take up production of light commercial vehicles.

Mutually Exclusive Investments (Projects):

Mutually exclusive investments directly compete with each other and acceptance one implies rejection of others.

Conventional Investments (Projects):

In a conventional project cash outlay occurs at the initial stage and thereafter all the cash flows take the form of cash inflows. It follows the pattern of -++++++ sign (where - sign implies cash outflow and +implies cash inflow). 
Non Conventional Investments (Projects):

In the case of a non conventional project, Cash outflows are mingled with cash inflow through out the life of the project. It takes the form of -++-+- sign pattern.

\section{Literature Review}

Many researches have been conducted on corporate capital budgeting practices. Many of these researches are directed towards various evaluation methods such as payback, internal rate of return (IRR), net present value (NPV), discounted payback, profitability index (PI). Gitman and Forrester's (1977) studied the Capital Budgeting techniques Used by Major U. S. Firms, Porwal's (1976) examined Capital Budgeting techniques and profitability. Rosenblatt and Jucker (1979) and Scott and Petty (1984) the use of techniques which recognize the time value of money. Klammer (1972) surveyed a sample of 369 firms from the 1969 and the results indicated increased use of techniques that incorporated the present value. James (1973) surveyed a random sample of 250 business firms. He found that firms considered the Internal Rate of Return model to be the most important model for decision-making. He also found that the majority of firms increased their profitability requirements to adjust for risk and considered defining a project and determining the cash flow projections as the most important and most difficult stage of the capital budgeting process. Kim and Edward (1981) surveyed the 1979 Fortune $100 \mathrm{CFO}$ about their 1975 and 1979 usage of techniques for evaluating capital budgeting projects. They found that in both years, the majority of the firms relied on a DCF method (either the IRR or the NPV) as the primary method and the payback as the secondary method. Marc Ross (1986) In an in-depth study of the capital budgeting projects of 12 large manufacturing firms and the results showed that firms relied rather heavily on the simplistic payback model, especially for smaller projects. In addition, when discounted cash flow techniques were used, they were often simplified. Andrews and Butler (1986) conducted similar investigation on the utilisation of capital budgeting techniques in South Africa based on 132 responses out of 500 companies. Their findings show that larger firms tended to employ more sophisticated capital budgeting techniques such as the DCF techniques. Jog and Srivastava (1991) provide direct empirical evidence on the capital budgeting process based upon a survey of large Canadian corporations. They explored many issues viz, the use of capital budgeting techniques, cash flow forecasting methods, risk analysis techniques and methods used to estimate the cost of capital and the cost of equity. His findings are most firms used multiple capital budgeting methods to assess capital investments; DCF methods were employed by more than $75 \%$ of our respondents to evaluate projects such as expansion-existing operations, expansion-new operations, foreign operations and leasing. Bierman (1993) finds that 73 of 74 Fortune 100 firms use discounted cash flow (DCF) analysis, with internal rate of return (IRR) being preferred over net present value (NPV). The payback period method also remains a very popular method in practice, though not as a primary technique. 93 per cent of the respondents use company-wide WACC for discounting free cash flows and 72 per cent use the discount rate applicable to project based on its risk characteristics. Drury and Tayles (1996) conducted a questionnaire survey which can provide an overview of current management accounting practices and they found that amongst 46 largest organizations in UK 63\% always used IRR, $50 \%$ always used NPV and 30\% always used the payback method. Hall (2000) further added similar evidence on South Africa with 65 respondents out of a total population of 300 . Toit and Pienaar (2005) also found that firms that undertake relatively large capital expenditures tend to prefer the IRR and the net present value (NPV) method. Recent studies have identified risk assessment and incorporation into capital budgeting decision making process crucial. Parry and Firer (1990) in that recognition found that 18 per cent of their respondents had no response to any technique, but that 61 per cent sometimes or often used sensitivity analysis. In India Chandra (1975) conducted a survey of twenty firms to examine the importance assigned to economic analysis of capital expenditures, methods used and its rationale for analyzing capital expenditures. The findings revealed that the most commonly used method for evaluating investments of small size is the PBP and for large size investments the ARR is used as the principal criterion. In a survey Pandey (1989) found payback as the most popular method. IRR was found to be the second most popular method. It was also found that the reasons for the popularity of payback were stated to be its simplicity to use and understand. Arshad (2012) Net present value and internal rate of return are the capital budgeting techniques mostly used to evaluate the projects or investments For individual projects IRR is used mostly to evaluate the project and NPV is preferable when the projects are mutually exclusive. But sometimes investors prefer to use NPV because it is easy to calculate and reinvest the cash flows at the cost of capital. And sometimes IRR is preferable because it gives answer in percentage and it is easy to understand.

\section{Data and Methodology}

Data used in the write up is in the nature of closed source and has been gathered from the verbal interview with the director of The company. To arrive at the decision to chose the best alternative ranking methodology using Net Present Value (NPV) and Internal Rate of Return (IRR) have been used.

a) NPV is the difference between present value of cash inflows and present value of cash outflows. Cash inflows that are separated by different periods are converted into equivalent present value.

$$
\mathrm{NPV}=\sum \mathrm{Ct} /(1+\mathrm{k})^{\wedge} \mathrm{t}-\mathrm{Co}
$$

[Where $\mathrm{Ct}=$ cash inflows occurring through out the project till $n$th period, $\mathrm{t}=1,2,3 \ldots \ldots \mathrm{n}, \mathrm{k}$ is the discounting rate which is firm's cost of capital \& Co is the initial cash outlay].

b) IRR is that rate which equates the present value of cash inflows with present value of cash outflow/outflows. It means that at IRR the NPV becomes zero. 


$$
\sum \mathrm{Ct} /(1+\mathrm{r})^{\wedge} \mathrm{t}-\mathrm{Co}=0
$$

[Where $\mathrm{Ct}=$ cash inflows occurring through out the project till $\mathrm{nth}$ period, $\mathrm{t}=1,2,3 \ldots \ldots \mathrm{n}, \mathrm{k}$ is the discounting rate which is firm's cost of capital \& Co is the initial cash outlay].

Trial and Error method has been used to arrive at. the discounting rate that makes NPV zero.

\section{The Case}

The Director of the Oil Refinery Company has never faced the situation as this ever before. He picked up the telephone to call the author and explained the unprecedented situation. The Company is situated at the banks of holly river The Ganges and is one the leading manufacturers of edible palm oil in West Bengal. The company imports crude palm mainly from Malaysia. The Plant and machineries are mainly imported from mainland China. The director himself selects the best option as regards selection of equipments. With the help of a technical engineer the cash flows are estimated throughout the life of the machines. The director uses simple NPV and IRR technique to rank alternatives. Hence, selects the best alternative. The purpose of the call was a serious confusion regarding selecting the best equipment out of two alternatives. The investment decision [Project] was mutually exclusive in nature i. e. selection of one resulting in rejection of other. The Oil Refinery Company required a Pellet Mill Oil Adding [PMOA] Machine to perform mixing operation. Triggered by the requirement the company received several quotations and subsequently scaled down to two best possible options. Both the suppliers were from China [Mainland]. As the projects were mutually exclusive, ranking was inevitable. At the time of ranking the two projects the unprecedented situation took place- NPV and IRR giving contradictory results as regards ranking of two projects. The Free On Board [FOB] costs were same for the two machineries and the amount was USD 12000. The technical person estimated that both white PMOA and green PMOA will last for three years with following inflows.

$\begin{array}{llll} & \text { Year 1 } & \text { Year 2 } & \text { Year 3 } \\ \text { White PMOA } & \text { USD 7000 } & \text { USD 9000 } & \text { USD 11030 } \\ \text { Green PMOA } & \text { USD 10000 } & \text { USD 9000 } & \text { USD 7000 }\end{array}$

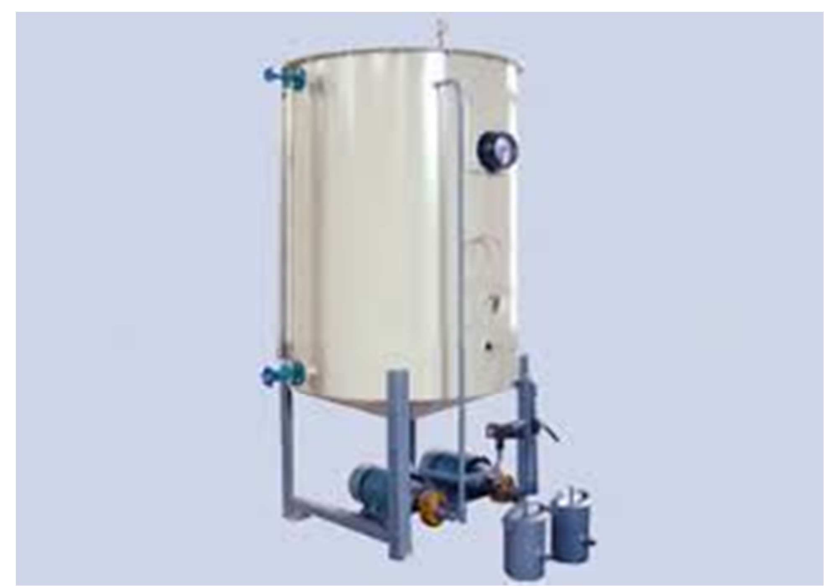

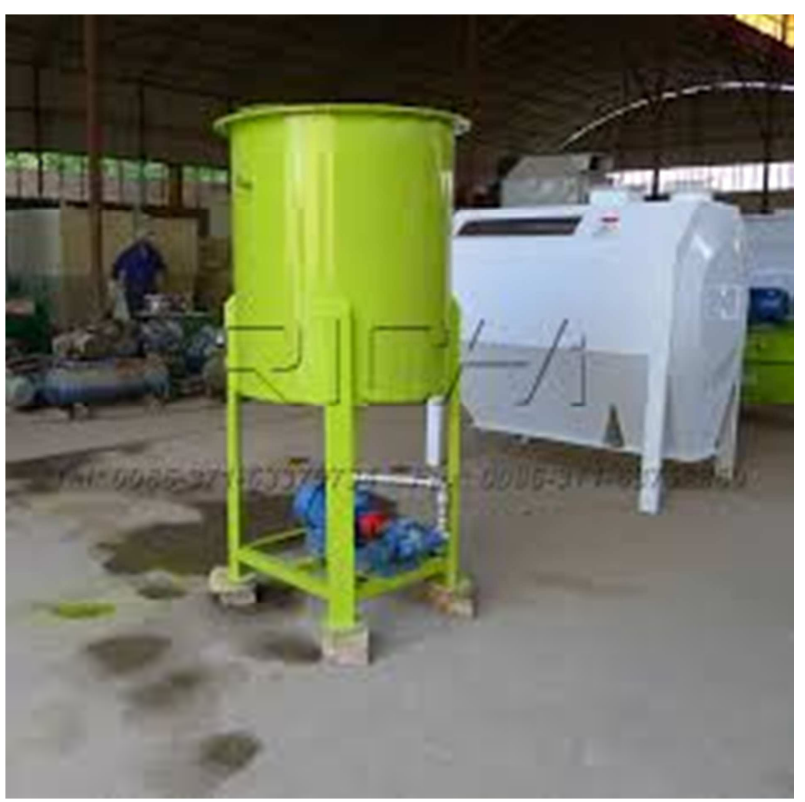

Figure 1. White Pellet Mill Oil Adding Machine \& Green Pellet Mill Oil Adding Machine.

\section{Application of Steps}

Estimation of Cost of Capital For the purpose of ranking the projects estimation of cost of capital was a pressing need. To find the NPV of a project [investment decision] cost of capital is used as the discounting factor. Estimation of cost of capital is a difficult and delicate task. The required rate of return was estimated to be $8 \%$. In absence of any specific source of funding Weighted Average Cost of Capital [WACC] should be used. As this purchase was funded by the amount taken as loan from the bank, approximate bank rate was set as required rate of return [Cost of Capital]. Decision Rule in case of independent projects, projects with NPV $>0$ are selected and all the profitable projects with NPV $>0$ are selected provided fund is not a constraint. Projects with $\mathrm{NPV}<0$ are rejected. A project with NPV $=0$ may or may not be selected. But as the particular instance is a case mutually exclusive investment decision ranking becomes inevitable and the project with higher NPV is to be selected. As regards IRR if IRR $>\mathrm{K}$ [cost of capital] an independent investment decision is taken. Investments with $\mathrm{IRR}<\mathrm{K}$ are due for outright rejection. An investment decision may or may not be taken if IRR=K. Again the decision rules are somewhat different for mutually exclusive investment decisions for ranking. Investment decision that results in highest IRR is selected.

\section{Results and Analysis}

Table 1 provides summarized information of the NPV profile of two mutually exclusive projects i. e. White PMOA and Green PMOA. It can be observed from the results that the NPV of White PMOA is $\$ 1095.35$ and NPV of Green PMOA is $\$ 1053.21$. Based on the decision rule, it is an obvious fact that White PMOA is selected and Green PMOA is rejected. 
Table 1. NPV Profile of Two Investments.

\begin{tabular}{lll}
\hline & White PMOA & Green PMOA \\
\hline Discounting Rate & $8 \%$ & $8 \%$ \\
Initial Investment & $(\$ 1,2000)$ & $(\$ 1,2000)$ \\
Cash inflow Year 1 & $\$ 7000$ & $\$ 1,0000$ \\
Cash inflow Year 2 & $\$ 9000$ & $\$ 9000$ \\
Cash inflow Year 3 & $\$ 1,1030$ & $\$ 7000.00$ \\
NPV & $\$ 10,953.50$ & $\$ 10,532.13$ \\
Ranking & Selected & Rejected \\
\hline
\end{tabular}

Applying Trial and Error method, using equation ..... (2) the IRR of the two investments are found out. Table 2 provides the information as regards the IRR of two machines.

Table 2. NPV at Forty Percent and Fifty Five Percent Discounting Rate.

\begin{tabular}{lll}
\hline & White PMOA & Green PMOA \\
\hline Discounting Rate & $49 \%$ & $55 \%$ \\
Initial Investment & $(\$ 1,2000)$ & $(\$ 1,2000)$ \\
Cash inflow Year 1 & $\$ 7000$ & $\$ 1,0000$ \\
Cash inflow Year 2 & $\$ 9000$ & $\$ 9000$ \\
Cash inflow Year 3 & $\$ 1,1030$ & $\$ 7000.00$ \\
NPV & $\$ 86.25$ & $\$ 77.47$ \\
\hline
\end{tabular}

Table 3. NPV at Fifty Percent and Fifty Six Percent Discounting Rate.

\begin{tabular}{lll}
\hline & White PMOA & Green PMOA \\
\hline Discounting Rate & $50 \%$ & $56 \%$ \\
Initial Investment & $(\$ 1,2000)$ & $(\$ 1,2000)$ \\
Cash inflow Year 1 & $\$ 7000$ & $\$ 1,0000$ \\
Cash inflow Year 2 & $\$ 9000$ & $\$ 9000$ \\
Cash inflow Year 3 & $\$ 1,1030$ & $\$ 7000.00$ \\
NPV & $(\$ 65.19)$ & $(\$ 47.67)$ \\
\hline
\end{tabular}

At $49 \%$ discounting rate the NPV of White PMOA is $\$ 86.25$ (Positive) and at 50\% discounting rate the NPV of White PMOA is $\$ 65.19$ (Negative). So it can be gauged from the figures that discounting rate that makes NPV of White PMOA equals to zero i. e. IRR lies in between $49 \%$ and $50 \%$. The IRR of white PMOA is found out by using the formula IRR=Lower Discounting Rate (Integer) + Positive NPV Due to Lower Discounting Rate/ Total of Positive and Negative NPV Or IRR= Higher Discounting Rate (Integer) - Negative NPV due to Lower Discounting Rate/ Total of Positive and Negative NPV. Hence IRR of white PMOA $=49 \%+86.25 /(86.25+65.19)=$ $49.56 \%$. Similarly the IRR of green PMOA is equals to $55.62 \%$. If IRR be the decision rule, it is obvious that green PMOA is selected and white PMOA is rejected. Table 4 provides the comprehensive ranking based on the parameters NPV and IRR.

Table 4. Comprehensive Ranking of Two Investments.

\begin{tabular}{lll}
\hline & Decision Rule: NPV & Decision Rule: IRR \\
\hline White PMOA & Selected & Rejected \\
Green PMOA & Rejected & Selected \\
\hline
\end{tabular}

There is contradicting result, as white PMOA is to be selected if the decision rule is NPV, whereas green PMOA is preferred as per the criteria of IRR.

The reason for this contradiction is the timing of cash flows of the projects. For white PMOA, largest inflows are occurring in later periods where the magnitude of discounting is severe, so with the increase in cost of capital the present value of cash inflows of white PMOA is decreasing drastically. For this particular reason at a lower discounting rate $(8 \%)$ the NPV of white PMOA is higher than green PMOA. But at a higher discounting rate $(24 \%)$ the situation gets reversed. Again at $16 \%$ cost of capital NPV of both white PMOA and green PMOA are almost equal \$7,789 and $\$ 7,793$ respectively. So at $16 \%$ discount rate the NPV profile of the both the project will intersect. This point is called Fisher's Intersection. For any discounting rate greater than intersection rate the NPV and IRR method will lead to consistent results regarding selection of project. The project with higher Internal Rate of Return (IRR) will have higher Net Present Value.

\section{Conclusions}

It is evident from the above discussion that for independent conventional projects there is no contradiction between NPV and IRR methods, as all profitable projects are selected and ranking of projects is not relevant. But for mutually exclusive projects where only the best among similar projects is selected ranking becomes a necessity. At times NPV and IRR may lead to contradictions in those cases. So the inevitable question is raised which of the two methods is best to select. To reach at a conclusion we can say that if we select white PMOA, the organization will be richer by additional $\$ 421.37$ It is better to be richer with additional cash than to earn higher rate of return. Net Present Value method is always consistent with share holder's wealth maximization principle. For unconventional projects Internal Rate of Return method gives multiple rates. To avoid those problematic situations the simple solution is to apply Net Present Value method. Hence purchase of white Pellet Mill Oil Adding machine would be a prudent decision for The Oil Refinery Company.

\section{References}

[1] Pandey, IM (2006), “Financial Management. Delhi: Vikash.

[2] Scheepers, Cor (2003), "Capital Finance Decisions For Project Managers- A Reflection On Current Methods,". Acta Commercii, Vol. 3, ISSN: 2413-1903.

[3] Arshad, Asma (2012), "Net Present Value is better than Internal Rate of Return,". Interdisciplinary Journal Of Contemporary Research In Business, VOL 4, NO 8, ISSN: 2073-7122

[4] Tufuor, Kofi, Nana, Antwi, \& Doku, Ntiamoah, James (2013), "Capital Budgeting Practices In Emerging Market Economies: Evidence From Listed Ghanaian Firms." Research Journal of Finance and Accounting, Vol. 4, No. 17, ISSN 2222-2847.

[5] Bierman Harold, Jr. "Comparing Net Present Value and Internal Rate of Return," QFINANCE [Brochure].

[6] Lutz, Jack. (2011), "IRR vs. NPV,” Forest Research Notes. Vol 8, No 1 .

[7] Lajos, Juhász (2011), "Net Present Value Versus Internal Rate of Return," Economics \& Sociology, Vol. 4, No 1,, ISSN 2071-789X, pp. 46-53. 
[8] Volkman, David A (1997), “A Consistant Yield-Based Capital Budgeting Method," Journal of Financial and Strategic Decision, Vol. 10 No. 3, pp. 76-88.

[9] Kalhoefer, Christian (2010), "Ranking of Mutually Exclusive Investment Projects - How Cash Flow Differences Can Solve The Ranking Problem," Investment Management and Financial Innovations, Vol. 7, Issue 2, pp. 81-86.
[10] Aho, Teemu, Virtanen, Ilkka (1983), “On Realationships Between ROI and IRR Under Inflation: A Constant Real Cash-Flow Case," Europen Journal of Operational Research, Vol. 13, pp. 256-267. 